\title{
Effect of pleading the fifth amendment on perceptions of guilt and morality
}

\author{
CLYDE HENDRICK \\ Kent State University, Kent, Ohio 44242 \\ and \\ DAVID R. SHAFFER \\ University of Georgia, Athens, Georgia 30601
}

\begin{abstract}
A simulated jury situation was used to study the effects of pleading the fifth amendment on inferences about an accused person's guilt and ratings of his morality. Subjects read a fabricated transcript of a grand jury proceeding for an embezzlement case in which an accused person either denied guilt for himself or took the fifth amendment and either denied guilt for another person or took the fifth amendment when questioned about the other person. Thus, the experiment was a 2 by 2 between-groups factorial design. Results showed that negative moral evaluation was in direct proportion to the frequency with which the fifth amendment was taken. Inferences of guilt showed a similar trend except that consistency of pleading for self and other also moderated inferences of guilt.
\end{abstract}

During the last few years, social psychology has become increasingly relevant to the law, as witnessed by a spurt of articles and applications (e.g., Rokeach \& Vidmar, 1973). In particular, research interest has focused on what may be called the effects of "extralegal" variables on decisions made in the courtroom.

Three categories of such extralegal variables have received attention. Defendant attributes and similarities to the jurors have been shown to affect jury decisions. For example, the degree of belief similarity between defendant and jurors affected perceptions of guilt and severity of recommended sentence (Mitchell \& Byrne, 1973). Other studies have focused on the characteristics of jurors. Personality variables such as authoritarianism have been related to the tendency of simulated jurors to convict defendants (Mitchell \& Byrne, 1973). A third area has been concerned with the effects of procedural and testimonial variables. As one example, Sue, Smith, and Caldwell (1973) studied the effects of inadmissible evidence on the decisions of simulated jurors.

The present study was concerned with a testimonial variable that seems not to have received previous experimental attention. This variable was withholding of information during testimony and its effect on simulated jurors-in everyday terms, the effects of pleading the fifth amendment.

The relevant portion of the fifth amendment states that "No person ... shall be compelled in any criminal case to be a witness against himself." This constitutional protection has an interesting and volatile history (Ellis,

Requests for reprints should be addressed to Clyde Hendrick. Department of Psychology, Kent State University, Kent, Ohio 44242.
1970). The privilege against self-incrimination arose in reaction to the procedures of the canonical courts in medieval England. Specifically, the reaction was against a required oath to give true sworn statements to any question posed by a legal interrogator. As Ellis (1970, p. 835) noted, the oath in its original form posed a cruel trilemma of contempt, perjury, or conviction for defendants.

Ellis (1970) stated that the privilege evolved not as a shield for the innocent but as a privilege of the guilty. However, as a legal principle, pleading the fifth amendment does not allow an inference of either guilt or innocence, since both guilty and innocent men may so plead (Hook, 1957, p. 13). But, as his major thesis, Hook attempted to show that invocation of the fifth amendment results in "a presumption of guilt or unfitness with respect to the issue in question which is relevant to inferences made in a nonlegal or moral context" (p. 13). That such a psychological reaction occurs seems to be a commonly held view.

The major purpose of the present study was to determine whether a stronger inference of guilt does in fact occur when an accused person pleads the fifth amendment in a simulated grand jury situation. There may be several psychological bases for such an attribution of guilt, including common sense postulates (innocent men have nothing to hide), balance pressures, and reactance to the withholding of information (Worchel \& Arnold, 1973). Thus, the major purpose of the experiment was to confirm that such an effect occurs. Despite the vast amount of speculation, there is no systematic data on the question.

A secondary purpose of the research was to explore the effects of withholding information about oneself as 
compared with withholding information about another person. There are numerous situations in which an accused person may talk freely about his own actions but plead the fifth amendment when questioned about another person. Both Hook (1957, p. 61) and Griswold $(1955$, p. 25) feel that this use of the fifth amendment is generally condoned, presumably because of some social proverb such as "people should not cause trouble for their neighbors." Informer seems to be a universally detested role, both in kindergarten and the criminal world.

Brief consideration indicates, however, that denying guilt for self and pleading the fifth with respect to another (or vice versa) will not be satisfactory to jurors in general without a great deal of motivational elaboration. The bare statement of denial in one instance and pleading the fifth in the second instance should create imbalance.

Consider a simple triad consisting of the accused person, other person, and heinous act, A. Assume a perceived + unit relation between the elements accused person and other person. If the accused denies $A$, a + sentiment relation is created between the accused and A. Pleading the fifth with respect to other should create a - sentiment relation between other and A, resulting in an imbalanced triad. One easy resolution is to change the accused $+A$ relation to an accused $-A$ relations, while retaining the + unit relation between the accused and other. In restoring balance, both the accused and other are viewed as "partners in crime" so to speak. Thus, if anything, pleading inconsistently might lead to a stronger inference of guilt than pleading consistently (either uniform denial of guilt for both the accused and other, or uniform pleading of the fifth amendment).

These questions were explored by having subjects read a short "case transcript" of a grand jury proceeding. Two critical variables were manipulated. In response to a question about his own guilt, an accused person either denied guilt for himself or plead the fifth amendment. In response to a question implicating another, an accused person either denied the implication of the other person or plead the fifth amendment. Thus the experiment was a 2 by 2 factorial between-groups design with the conditions self-deny-other-deny, self-deny-other-fifth, self-fifth-other-deny, and self-fifth-other-fifth. Following Hook's (1957) discussion, rating questions were included which assessed both inferences about the accused person's probable guilt and his moral character.

\section{METHOD}

\footnotetext{
Subjects

Students from an introductory psychology course served as subjects in a large testing session early in the quarter. Subjects received the experimental materials in booklet form in manila envelopes which were randomly distributed. Both male and female subjects served in about equal proportions, but no attempt was made to retain sex as a variable. Number of subjects per condition was as follows: self-deny-other-deny $=49$; self-deny-other-fifth $=58 ;$ self-fifth-other-deny $=56$; self-fifth-other-fifth $=51$.
}

\section{Experimental Booklets}

The first page of the booklet, entitled The Grand Jury Project explained the nature of the experiment. The nature of a grand jury was described as well as the meaning of indictment. Subjects were asked to role play the part of a grand juror and read a portion of a transcript of some testimony taken from an embezzlement case. It was stressed that we were interested in subjects' impressions based on partial information and (to preclude protests of insufficient information) that we understood that their judgment could conceivably differ if they had read the entire transcript.

The second page was a constant for all conditions. It consisted of a (fabricated) series of questions and answers that set the stage for the manipulation of the variables. This material was as follows:

\section{CASE B3369 - EIGHTH FEDERAL DISTRICT COURT}

The testimony presented below was taken by the grand jury from the accused person. In this sense, the testimony is probably the most important in the case, although there were several other witnesses who presented evidence as well.

PROSECUTOR: How long have you worked for the Mercantile Trust Bank?

ACCUSED: Six years.

PROSECUTOR: What were your duties at the bank?

ACCUSED: Basically, I was a teller.

PROSECUTOR: Didn't you have additional duties as well?

ACCUSED: Yes.

PROSECUTOR: What were those duties?

ACCUSED: I was responsible for the physical safety of the books, and guarding them so that only authorized personnel had access to them.

PROSECUTOR: So you had physical charge of the books - uh, you were guardian of them so to speak?

ACCUSED: Yes, that's right.

PROSECUTOR: Did you receive extra compensation for those duties?

ACCUSED: Yes.

PROSECUTOR: Did your job also involve any bookkeeping in the sense of entering figures in the ledger?

ACCUSED: No.

PROSECUTOR: So, the job in no way involved keeping the books, except physically in the sense of protecting them.

ACCUSED: Yes, that is correct.

PROSECUTOR: Do you know the basic principles of accounting and bookkeeping?

ACCUSED: Well, uh, I had the rudiments of those courses, but that was several years ago in business college. I've forgotten most of it.

PROSECUTOR: Well, now, Mr. lets review the situation for a moment. A large amount of money has been embezzled from the 
Mercantile Trust over the last two years. The embezzlement was very skillfully concealed by double entry bookkeeping until discovered by the auditors last month. The other people who had access to the books have ironclad alibis that they are not guilty.

I would like to ask you-did you ever allow anyone other than authorized persons to have access to those books while you were physically taking care of them?

The manipulation of other involvement was introduced by the accused person's response to this question. In the deny condition, that accused person stated, "No, absolutely not. To my knowledge no unauthorized person ever looked at the books." In the fifth amendment condition, the accused person stated "I prefer to take the fifth amendment in response to this question. Therefore I decline to answer."

Regardless of which response the accused person gave, the prosecutor then proceeded:

PROSECUTOR: Mr. _ I ask you directly-did you change the entries in the bank books? In other words did you "doctor" those books to cover illegal embezzlement of funds?

The accused person's response manipulated self-involvement. In the deny condition, the accused person stated, "No, I certainly did not." In the fifth amendment condition, the accused person stated, "I prefer to take the fifth amendment in response to this question. Therefore I decline to answer."

Regardless of which answer the person gave, the transcript was concluded by the prosecutor stating "OK, Mr.___ _ , you are excused; no further questions at this time."

\section{Rating Form}

The rating form followed the transcript. It included four questions assessing willingness to indict and inference of guilt (these items are given in the RESULTS section). Each item was rated on a nine-point scale with appropriate end labels (e.g., very likely accused is guilty) and a center label (uncertain).

Moral evaluation of the accused person was obtained from one rating question and 10 trait ratings. These items were also rated on a nine-point basis, and, for the traits, only end labels were used (e.g., very honest, very dishonest).

Finally, one question assessed the adequacy of the manipulations.

\section{RESULTS}

\section{Manipulation Check}

The item "How many times did the accused person take the fifth amendment?" was included as a check question. The response categories were none, one, two, and three. Over all conditions, $90.7 \%$ of the subjects checked the correct category. The four categories were given weights of $0,1,2$, and 3 , respectively, and subjected to an analysis of variance. Both main effects were highly significant (Fs $>300$ ), but the interaction was not significant $(F=3.08, \mathrm{df}=1 / 210, \mathrm{p}<.08)$.

The mean score of the self-deny-other-deny condition was .16 (with 0 as the "perfect" score); .97 for the self-deny-other-fifth condition; .95 for the self-fifth-other-deny condition (with 1.00 as the perfect score in each case); and 1.92 in the self-fifth-other-fifth condition (with 2.00 perfect).
Thus, the subjects adequately perceived the manipulations over all conditions, and all subjects were retained for further data analyses.

\section{Perceptions of Moral Character}

One connotation of pleading the fifth amendment seems to be a slight moral taint attached to the pleader. By so pleading, the accused person may withhold relevant information that could conclude the issue, thereby creating some sense of moral condemnation. One main dependent rating measure and the ten trait ratings were included to study this process.

The most important rating item was "How would you describe the accused person's moral character?" An analysis of variance revealed that both main effects (but not the interaction) were significant $(F$ for self $=8.5$, $\mathrm{df}=1 / 210, \mathrm{p}<.005 ; \mathrm{F}$ for other $=5.6, \mathrm{p}<.02)$. As expected, the accused person's morality rating was directly proportional to how often he pleaded the fifth amendment. An accused person not pleading the fifth (self-deny-other-deny) was rated as most moral, 6.0; while the person pleading twice was viewed as least moral, 4.9. The other two conditions were intermediate: self-deny-other-fifth $=5.4$, self-fifth-other-deny $=5.3$.

Ratings for integrity followed the same pattern as the moral character ratings. Ratings on most of the other traits were generally uniformative.

\section{Inferences of Guilt}

The main ratings of interest were the perceptions or inferences of guilt. Four rating questions assessed guilt inferences. Means for these measures are shown in Table 1 for the four experimental conditions, along with relevant $F$ ratios.

The pattern of mean ratings allows two general conclusions. First, it was considerably to the accused person's benefit to deny guilt. Secondly, there was a tendency for this benefit to accrue as a function of the accused person's consistency in pleading; i.e., either deny guilt for both self and other, or plead the fifth for both self and other.

The first item asked, "Based on the available testimony, what would you, as an individual grand jury member, recommend to the jury as a whole?" The means are shown in the first row of Table 1. As indicated, subjects were less willing to indict when the accused person denied guilt for self $(\overline{\mathrm{M}} s=5.6,6.2)$ than when the accused person pleaded the fifth amendment (Ms $=7.4,6.9)$. The main effect of self was highly significant $(F=24.3, p<.01)$.

Willingness to indict was moderated to a slight extent by the consistency of the accused person's position. The mean for self-deny-other-fifth, 6.2, was slightly larger than the mean for self-deny-other-deny, 5.6. Conversely, the mean for self-fifth-other-deny, 7.4, was slightly larger than the mean for self-fifth-other-fifth, 6.9. The interaction was significant $(F=4.2, p<.05)$. 
Table 1

Mean Ratings for Inferences of Guilt

\begin{tabular}{|c|c|c|c|c|c|c|c|}
\hline \multirow[b]{3}{*}{ Question } & \multicolumn{2}{|c|}{ Deny Guilt for Self } & \multicolumn{2}{|c|}{ Plead 5 th for Self } & & & \\
\hline & \multirow{2}{*}{$\begin{array}{c}\text { (1) } \\
\text { Deny } \\
\text { for } \\
\text { Other }\end{array}$} & \multirow{2}{*}{$\begin{array}{l}\text { (2) } \\
5 \text { th } \\
\text { for } \\
\text { Other }\end{array}$} & \multirow{2}{*}{$\begin{array}{c}\text { (3) } \\
\text { Deny } \\
\text { for } \\
\text { Other }\end{array}$} & \multirow{2}{*}{$\begin{array}{l}(4) \\
5 \text { th } \\
\text { for } \\
\text { Other }\end{array}$} & \multicolumn{3}{|c|}{ F Ratios } \\
\hline & & & & & Self & Other & $\begin{array}{l}\text { Inter- } \\
\text { action }\end{array}$ \\
\hline 1. Indict or not? & $5.6^{\mathrm{a}}$ & $6.2^{\mathrm{a}}$ & $7.4^{\mathrm{b}}$ & $6.9^{\mathrm{b}}$ & $24.3 * *$ & .1 & $4.2 *$ \\
\hline 2. Is accused guilty? & $4.8^{\mathrm{a}}$ & $5.9^{\mathrm{b}}$ & $6.8^{b}$ & $6.4^{\mathrm{b}}$ & $24.6 * *$ & 2.3 & $8.1 * *$ \\
\hline 3. Is someone else guilty? & $6.0^{\mathrm{a}}$ & $5.9^{\mathrm{a}}$ & $5.2^{\mathrm{b}}$ & $5.3^{\mathrm{ab}}$ & $5.9 *$ & .0 & .3 \\
\hline 4. Are both accused and someone else guilty? & $5.8^{\mathrm{a}}$ & $6.9^{b}$ & $6.8^{\mathrm{b}}$ & $5.9^{\mathrm{a}}$ & .0 & .2 & $10.8 * *$ \\
\hline
\end{tabular}

Note-The higher the score, the more definite the inference of guilt or willingness to indict. Means with no superscripts in common differed at the .05 level by the Newman-Keuls test. Only the following comparisons were included: 1 vs. 2 , 3 vs. 4,1 vs. 3,2 vs. 4.

$* p<.05$

${ }^{* *} p<.01$

Almost the same pattern of results was obtained for the second question "Based on the available testimony, what is your own personal opinion as to how likely it is that the accused person is guilty?"

The third questions asked, "What is your own personal opinion as to how likely it is that someone else (and not the accused) is guilty?" For this measure, a high score meant "very likely someone else is guilty," and a low score meant "very unlikely someone else is guilty." The means for this item in Table 1 show higher likelihood ratings for other when guilt was denied for self (or conversely, less likelihood that other was guilty when pleading the fifth for self, $F=5.9, p<.05$ ). For this item, consistency of the information had no effect.

The fourth question asked, "What is your own personal opinion as to how likely it is that both the accused person and someone else are guilty?" The effect of consistency of information was most potent for this item. Neither main effect was significant, but a strong interaction occurred $(\mathrm{F}=10.8, \mathrm{p}<.01)$. Perception of guilt was about the same for both consistent denial (5.8) and consistent pleading of the fifth (5.9) but was considerably higher for the two inconsistent conditions: 6.9 for self-deny-other-fifth and 6.8 for self-fifth-other-deny. Clearly information consistency affected subjects' perceptions of guilt with inconsistency leading to stronger guilt inferences.

\section{DISCUSSION}

The results clearly indicated that an accused person was less likely to be considered as guilty when he denied guilt than when he took the fifth amendment. Thus, the common sense intuition was completely confirmed.

The presumed effects of consistency of pleading were less strongly confirmed except for Item 4, "Are both the accused and someone else guilty?" In retrospect, this item may well have been the most sensitive and appropriate measure. A careful reading of the transcript seems to imply that two people were required for the embezzlement, the accused person to surrender physical control of the book and someone else with bookkeeping skills to actually hide the crime. If so, a question asking for guilt of both persons should be most sensitive to inconsistency in pleading.

It is worth noting that the decision to measure moral evaluation separate from inference of guilt was justified by the results. As noted, for Item 4, strength of inference was the same for both denial and consistent pleading of the fifth amendment. But the accused person was rated as least moral when pleading the fifth twice. Very likely, subjects were willing to morally condemn the person for withholding information from them, perhaps because of reactance pressures (Worchel \& Arnold, 1973). But subjects were not willing to use moral indignation as a basis for inferences of guilt. Presumably guilt inferences were determined by the information value of the communication. At any rate, this distinction between jurors' moral evaluations and their inferences of guilt seems important and ought to be systematically explored in future work.

\section{REFERENCES}

Ellis, D. D., JR. Vox populi v. suprema lex: A comment on the testimonial privilege of the tifth amendment. Iow'a Law Riview, 1970, 55, 829-80.3.

Griswold, E. N. The 5 th amendment today. Cambridge, Mass: Harvard University Press. 1955.

Ноок, S. Common se'nse and the fifth amendment. New York: Criterion Books. 1957.

Mitchell, H. E., \& Byrne, D. The defendant's dilemma: Effects of jurors attitudes and authoritarianism on judicial decisions. Journal of Personality and Social Psychology, 1973, 25, 123-129.

Rokeach, M. \& Vidmar, N. Testimony concerning possible jury bias in a Black Panther murder trial. Journal of Applied Social Psivchology, 1973, 3, 19-29.

Sue, S., Smith, R. E., \& Caldwell, C. Effects of inadmissible evidence on the decisions of simulated jurors: A moral dilenma. Journal of Applied Social Psychology, 1973, 3. 345-353.

Worchel, S.. \& ARnold, S. E. The effects of censorship and attractiveness of the censor on attitude change. Journal of Experimental Social Psychology, 1973, 9, 365-377.

(Received for publication June 11, 1975.) 